\title{
Cardiotoxicity reduction induced by halofantrine entrapped in nanocapsule devices
}

\author{
Elaine Amaral Leite ${ }^{\mathrm{a}}$, Andrea Grabe-Guimarães ${ }^{\mathrm{a}, \mathrm{b}}$, Homero Nogueira Guimarães ${ }^{\mathrm{c}}$, \\ George Luiz Lins Machado-Coelho ${ }^{\mathrm{a}, \mathrm{b}}$, Gillian Barratt ${ }^{\mathrm{d}}$, Vanessa C.F. Mosqueira ${ }^{\mathrm{a}, \mathrm{b}, *}$ \\ ${ }^{a}$ Núcleo de Pesquisa em Ciências Biológicas (NUPEB), ICEB, Universidade Federal de Ouro Preto (UFOP), Ouro Preto, Minas Gerais, Brazil \\ ${ }^{\mathrm{b}}$ Departamento de Farmácia, Escola de Farmácia, Universidade Federal de Ouro Preto (UFOP), Ouro Preto, Minas Gerais, Brazil \\ ${ }^{\mathrm{c}}$ Departamento de Engenharia Elétrica, Escola de Engenharia, Universidade Federal de Minas Gerais (UFMG), Belo Horizonte, Minas Gerais, Brazil \\ ${ }^{\mathrm{d}}$ UMR CNRS 8612, Faculté de Pharmacie, Université de Paris-Sud, 92296 Châtenay-Malabry, France
}

Received 21 December 2005; accepted 19 December 2006

\begin{abstract}
The main objective of the present study was to evaluate the reduction in halofantrine (Hf) toxicity, an antimalarial drug frequently associated with QT interval prolongation in electrocardiogram, by its entrapment in poly- $\varepsilon$-caprolactone nanocapsules $(\mathrm{NC})$. The acute lethal dose ( $\left.\mathrm{LD}_{100}\right)$ of $\mathrm{Hf} . \mathrm{HCl}$ experimentally observed was $200 \mathrm{mg} / \mathrm{kg}$ whereas the calculated $\mathrm{LD}_{50}$ was $154 \mathrm{mg} / \mathrm{kg}$. In contrast, the LD 100 for Hf-NC was $300 \mathrm{mg} /$ $\mathrm{kg}$ with a longer mean time to death than $\mathrm{Hf} . \mathrm{HCl}$. The calculated $\mathrm{LD}_{50}$ was $249 \mathrm{mg} / \mathrm{kg}$ for Hf-NC. The Hf entrapped in PCL NC presented a greater efficacy than PLA-PEG NC and than $\mathrm{Hf}$ solution in $P$. berghei-infected mice at $1 \mathrm{mg} / \mathrm{kg}$. The cardiovascular parameters, ECG and arterial blood pressure, were evaluated in anaesthetized Wistar rats after the IV administration of a single, especially high dose (100 and $150 \mathrm{mg} / \mathrm{kg}$ ) of halofantrine base loaded-nanocapsules (Hf-NC) or halofantrine chlorhydrate (Hf.HCl) solution. It was observed that Hf solution caused prolongation of the QT and PR intervals of the ECG; however, this effect was significantly $(P<0.001)$ reduced when Hf was administered entrapped in nanocapsules. The treatment with $\mathrm{Hf} . \mathrm{HCl}$ induced a pronounced bradycardia and severe hypotension leading to death. The effect of Hf-NC upon heart rate was reduced from 58 to $75 \%$ for 100 and $150 \mathrm{mg} / \mathrm{kg}$, respectively, when compared with $\mathrm{Hf}$. HCl solution. These findings show that the encapsulation of halofantrine reduces the QT interval prolongation of ECG in rats and suggest that a modification of drug distribution was possible by using nanocapsules. Hf encapsulation was the main factor responsible for the significant reduction in cardiac toxicity observed.
\end{abstract}

(C) 2007 Elsevier Inc. All rights reserved.

Keywords: QT interval prolongation; Halofantrine; Nanocapsules; Drug carriers; Cardiotoxicity; Lipophilic drug

\section{Introduction}

Malaria is the most important parasitic infection in humans and the second largest cause of mortality in the world, killing more than one million people each year (Greenwood et al., 2005). The most serious cases of disease occur through

\footnotetext{
* Corresponding author. Universidade Federal de Ouro Preto, Escola de Farmácia, Rua Costa Sena, 171, Centro - Ouro Preto, 35400000 Minas Gerais, Brazil. Tel.: +55 313559 1638; fax: +55 3135591628 .

E-mail address: mosqueira@ef.ufop.br (V.C.F. Mosqueira).
}

infection by Plasmodium falciparum, causing considerable morbidity and mortality (Guerin et al., 2002). The same species induces a complicated form of malaria known as severe malaria characterized by acute renal failure and circulatory collapse, followed by coma and death (Warrell et al., 1990). In this case, intravenous (IV) antimalarial drug administration is necessary.

Previous studies showed that many strains of $P$. falciparum have developed resistance to antimalarial drugs, mainly against chloroquine and less frequently against quinine (ter Kuile et al., 1993; Wongsrichanalai et al., 2002). In populations with multi-drug-resistance, an IV formulation of halofantrine would be a useful alternative to treat severe 
malaria because it acts rapidly against blood erythrocytic stages of Plasmodium (Bryson and Goa, 1992). However, halofantrine exhibits low bioavailability by the oral route and has a potential arrhythmogenic effect, leading to a prolongation of the QT interval in the electrocardiogram (ECG), as demonstrated in humans (Krishna et al., 1993; Matson et al., 1996; Olivier et al., 1999; Abernethy et al., 2001) and other mammals (Batey et al., 1997; Lightbown et al., 2001). The QT interval prolongation is associated with episodes of torsade de pointes (Crumb and Cavero, 1999), severe ventricular arrhythmia, and sudden death in patients treated with $\mathrm{Hf}$ (Nosten et al., 1993). Krishna et al. (1993) have formulated and carried out clinical trials with a parenteral halofantrine preparation administered by slow IV infusion, but they have observed local toxic effects and a moderate QT interval prolongation, both in patients with acute malaria as well as in those in convalescence.

Therefore, a new approach to optimise the action of halofantrine by improving their therapeutic index needs to be developed. One possibility consists in modifying the distribution of the drug by entrapping it in a carrier system such as nanocapsules (Barratt, 2003) without altering its chemical structure nor its mechanism of action. Nanocapsules (NC) have an oily core, in which lipophilic drugs can be dissolved or dispersed, surrounded by a polymeric biodegradable membrane. They are part of a family of nanometric devices, which can control delivery and modify the distribution of an active substance to reach specific sites in the body or to protect vital organs from toxic effects (Lasic, 1998). In order to obtain an effective and suitable parenteral formulation of halofantrine to be administered in bolus by means of the intravenous route for the treatment of severe malaria, halofantrine free base was entrapped in nanocapsules (Mosqueira et al., 2004). In this way, a small sized, dispersed form of this insoluble drug can be obtained in an aqueous and isotonic medium, suitable for IV administration. A similar preparation of Hf nanocapsules was previously evaluated in mice and showed a slight improvement in antimalarial efficacy when compared to halofantrine solution, with a concomitant reduction of general toxicity (Mosqueira et al., 2004).

The main goal of the present work was to evaluate the cardiotoxicity of halofantrine in nanocapsules compared to halofantrine solution by analysing electrocardiogram parameters, particularly QT interval prolongation, and arterial blood pressure changes in anaesthetized Wistar rats, followed by IV injection of a single especially high dose of halofantrine. Efficacy and acute toxicity studies were also performed in order to compare nanocapsules of halofantrine obtained from poly- $\varepsilon-$ caprolactone polymer with other biodegradable NC used in previous studies.

\section{Materials and methods}

\section{Drugs and reagents}

Halofantrine chlorhydrate ( $\mathrm{Hf} . \mathrm{HCl})$ was provided at no charge from Smith Kline Beecham (UK). Poly- $\varepsilon$-caprolactone
(PCL) average $M_{n}$ 42,500, Poloxamer 188 (non-ionic surfactant) and dimethylacethamide (DMA) were provided by SigmaAldrich (USA). Epikuron 170 (70\% soy phosphatidylcholine) was purchased from Lucas Meyer (France). Miglyol 810N was kindly provided by Hulls (Germany). PEG 300 was provided by Synth (Brazil). The solvents were of analytical grade and all other chemicals were commercially available. Water was purified by reverse osmosis (Symplicity System 185, Millipore USA).

\section{Preparation of halofantrine nanocapsules and solution}

The free base was prepared by treating a solution of Hf salts, as previously described (Porter et al., 1996). Nanocapsules were obtained by interfacial polymer deposition following solvent displacement, as previously described by Fessi et al. (1989). NC was prepared with $60 \mathrm{mg}$ of polymer (PCL) dissolved in $10 \mathrm{ml}$ of acetone solution containing $75 \mathrm{mg}$ of Epikuron 170, $250 \mu \mathrm{l}$ of Miglyol $810 \mathrm{~N}$ and halofantrine free base $(1-10 \mathrm{mg} / \mathrm{ml})$. This organic solution was poured into $20 \mathrm{ml}$ of external aqueous phase containing $75 \mathrm{mg}$ of Poloxamer 188 under agitation. The solvents were evaporated under reduced pressure (Laborota 4000, Heidolph Instruments, Germany) until a final volume of $10 \mathrm{ml}$ was attained. For the study of antimalarial activity, PLAPEG diblock copolymer average Mw 66,000 (20\% PEG Mw 5000, Alkermes, USA) was used to obtain surface-modified NC using the method described by Mosqueira et al. (2004). A parenteral solution of halofantrine was prepared by dissolving the $\mathrm{Hf} . \mathrm{HCl}$ in dimethylacetamide-PEG $300(40: 60 \mathrm{v} / \mathrm{v})$ and further diluting it in 5\% glucose, according to the method described by Krishna et al. (1993). Although only one formulation was polydisperse $(10 \mathrm{mg} / \mathrm{kg})$, all of them were filtered through a $0.45 \mu \mathrm{m}$ sterile filter before iv injection to withdraw eventual embolic material. The control formulations (without drug) were also administered in the volume corresponding to the Hf formulations, injected at a dose of $150 \mathrm{mg} / \mathrm{kg}$, ensuring that these vehicles would not affect cardiovascular parameters.

\section{Determination of halofantrine encapsulation}

The determination of halofantrine content was performed by HPLC as previously described by Mberu and Muhia (1992). The percentage of drug loaded in nanocapsules was calculated by the difference between the total quantity of drug in the colloidal suspension minus the free drug in the external aqueous phase divided by the total quantity of drug in the colloidal suspension $\times 100$. The free drug in the external aqueous phase (ultrafiltrated) was obtained by ultrafiltration/ centrifugation de $400 \mu \mathrm{l}$ of NC suspension at $400 \mathrm{~g}$ for $15 \mathrm{~min}$ in an AMICON device (Microcon, molecular weight cut-off 100,000 Millipore $\left.{ }^{\circledR}\right)$. The amount of halofantrine bound to the ultrafiltration membrane was estimated by removing the membrane from the device. The membrane was rinsed with MilliQ water, immersed in $500 \mu \mathrm{l}$ acetonitrile, vortex-mixed for $15 \mathrm{~min}$, centrifuged, and the Hf content assayed in the supernatant. 


\section{Nanocapsule characterization}

The zeta potential, mean size and polydispersity index of the nanocapsule population were determined by Laser Doppler Anemometry (LDA) and Photon Correlation Spectrometry (PCS), respectively, using Zetasizer 3000 HS (Malvern Instruments, UK) after 250-fold dilution of the colloidal suspension in $\mathrm{NaCl} 1 \mathrm{mM}$. The conductivity of all $\mathrm{NC}$ dilutions was maintained at $120 \mu \mathrm{S} / \mathrm{cm}$. The measurements were performed at constant $\mathrm{pH}$ 7.1, determined by the instrument.

\section{Determination of acute lethal dose $\left(L D_{50}\right)$}

All procedures related to the use of animals in these studies were reviewed and conform to the Ethical Principles of Animal Experimentation (Brazilian College of Animal Experimentation/COBEA, 1991). Male Wistar rats weighing $250 \pm 50 \mathrm{~g}$ had the femoral vein catheterized under anaesthesia. Twenty-four hours after surgery, doses of $100 \mathrm{mg} / \mathrm{kg}$ to $300 \mathrm{mg} / \mathrm{kg}$ of Hf.HCl or Hf-NC, containing $10 \mathrm{mg} \mathrm{Hf} / \mathrm{ml}$ of colloidal suspension, were administered by the IV route to conscious animals. Toxic effects and death were observed over $24 \mathrm{~h}$.

\section{Antimalarial efficacy of NC formulations}

An inoculum of Plasmodium berghei NK65 clhoroquine sensible strain-infected erythrocytes was prepared from an infected Swiss mouse with rinsing parasitemia (15\%). Mice were infected by IV route with one million $P$. bergheiparasitized red blood cells in $0.2 \mathrm{ml}$ saline (day 0 ). The animals were randomly divided into five groups of 5 and treated 3 days after infection by the IV route with a single dose of halofantrine $(1 \mathrm{mg} / \mathrm{kg})$ in different formulations. Thin blood smears were made from tail blood on days 3 (before treatment), 5, 10,14, and 25 (after infection). Parasitemia levels were determined on Giemsa-stained smears by counting at least 3000 cells $(1000 \times$ magnification).

\section{Determination of cardiovascular parameters}

Male Wistar rats $(250 \pm 50 \mathrm{~g})$ were randomly distributed into six experimental groups: two groups received $\mathrm{Hf} . \mathrm{HCl}$ (doses of 100 and $150 \mathrm{mg} / \mathrm{kg}$ ) diluted in a solvent composed of dimethylacetamide (DMA), PEG 300 and glucose, prepared according to the method described by Krishna et al. (1993); two groups received Hf-NC (100 and $150 \mathrm{mg} / \mathrm{kg}$, at $10 \mathrm{mg} \mathrm{Hf} / \mathrm{ml})$, as described above. The other two groups received control solutions containing only vehicles: the solvent mixture or unloaded NC.

The animals were anaesthetized with $70 \mathrm{mg} / \mathrm{kg}$ sodium thiopental using the intraperitoneal route. When the anaesthesia reached the appropriate depth, the animals were tracheotomized to facilitate breathing. The femoral artery and vein were catheterized to permit record of arterial blood pressure (BP) and IV drug administration, respectively. The catheters were previously filled with $1 \%$ heparin in $0.9 \% \mathrm{NaCl}$ sterile solution. Arterial BP was monitored with P23XL pressure transducer
(Spectramed, USA) connected to a signal conditioning system. Limb read II ECG was recorded continuously using subcutaneous needle electrodes connected by a shielded cable to a biopotential amplifier. The blood pressure signal conditioning system and the biopotential amplifier were designed and built in our laboratory. The output signals of these systems were sampled at $600 \mathrm{~Hz}$ by a 12-bits H/D conversion board (DI 200, DATAQ Instruments, USA) and stored on a PC.

The solutions of Hf.HCl, Hf-NC and vehicles were injected at doses of 100 and $150 \mathrm{mg} / \mathrm{kg}$ at a rate of approximately $2.0 \mathrm{ml} /$ min. Records were taken for 10 and 15 min before and after injection of the different formulations of Hf, respectively. Thereafter, segmented registers of $30 \mathrm{~s}$ were performed every $5 \mathrm{~min}$ up to $30 \mathrm{~min}$ after the injection of the different solutions. The stored records were analysed off-line and included measures of QT (interval between the beginning of the Q wave and the end of the T wave of ECG), RR (interval between two R waves of ECG), PR (interval between the beginning of the $\mathrm{P}$ wave and the end of the $\mathrm{R}$ wave) and QRS (interval from the beginning of the $\mathrm{Q}$ wave to the end of the $\mathrm{S}$ wave) intervals. To attempt to correct for heart rate dependence, the QT interval was corrected using Fridericia's formula $\left(\mathrm{QT}_{\mathrm{c}}=\mathrm{QT} /(\mathrm{RR})^{1 / 3}\right)$. These parameters were measured before and after injection of the Hf formulations or calculated (Fridericia's formula) from register segments for each animal at different times, for segments containing from 4 to 8 heart cycles, depending on the heart frequency. The variations in each ECG parameter were calculated as follows: $\Delta \mathrm{QT}$ is the QT mean after drug injection minus QT mean before drug injection divided by QT mean before drug injection multiplied by 100 .

\section{Statistics}

Values are expressed as mean \pm standard error of mean. The value of each parameter before drug administration was used as the covariate. The difference among experimental groups was tested by covariance analysis. The percentage of variation observed at each time was compared using the Kruskal-Wallis test due to the fact that the data may not be distributed normally. Student's $t$ test was used to compare parasitemia between groups. Differences were considered statistically significant when the $P$ values were lower than 0.05 .

\section{Results}

\section{Nanocapsules characterization}

NCs are a suitable carrier for Hf because the free base is very soluble in oil $(>180 \mathrm{mg} / \mathrm{ml})$. It has a favorable octanol-water partition coefficient ( $\log P=8.5$ ) (Humberstone et al., 1996). A high drug concentration was obtained in the final colloidal suspension, and the drug was encapsulated with a yield of more than $95 \%$ (data not shown). Table 1 shows the effect of different halofantrine concentrations on NC size, polydispersity, and $\zeta$ potential. The mean diameter of the $\mathrm{NC}$ with $1.0 \mathrm{mg} / \mathrm{ml}$ of $\mathrm{Hf}$ is $191 \mathrm{~nm}$ as determined by PCS. This formulation was monodisperse $(\mathrm{PI}<0.3)$. The size of the particle increases 
Table 1

Physico-chemical characteristics of nanocapsules formulations ${ }^{a}$

\begin{tabular}{llll}
\hline $\begin{array}{l}\mathrm{Hf} \text { base }(\mathrm{mg} / \mathrm{ml}) \\
\mathrm{NC}\end{array}$ & $\begin{array}{l}\text { Mean size } \pm \mathrm{SD}^{b} \\
(\mathrm{~nm})\end{array}$ & $\begin{array}{l}\text { Polydispersity } \\
\text { index }\end{array}$ & $\begin{array}{l}\zeta \text { potential } \pm \mathrm{SD} \\
(\mathrm{mV})^{d}\end{array}$ \\
\hline 0 & $245 \pm 2.6$ & 0.193 & $-26.7 \pm 0.8$ \\
1 & $191 \pm 0.6$ & 0.277 & $-25.7 \pm 3.0$ \\
5 & $504 \pm 158$ & 0.630 & $-1.6 \pm 1.4$ \\
10 & $416 \pm 38$ & 0.350 & $+10.9 \pm 1.2$ \\
\hline
\end{tabular}

${ }^{a}$ Nanocapsules formulations composed of $\mathrm{PCL}=$ poly- $\varepsilon$-caprolactone $(6 \mathrm{mg}$ of polymer/ml of colloidal suspension), ${ }^{b}$ standard deviation $(n=3)$ of the population reported by the instrument; ${ }^{c}$ monodispersed samples $(\mathrm{PI}<0.3)$; ${ }^{d} n=3$, measurement after dilution $1: 250$ in $1 \mathrm{mM} \mathrm{NaCl}$.

when increasing halofantrine concentrations were associated with the system. The larger diameter obtained with the concentration of $5.0 \mathrm{mg} / \mathrm{ml}$ was correlated with a reduced $\zeta$ potential $(-1.6 \mathrm{mV})$ that would be predisposed to aggregation due to reduced interfacial charge of the colloidal particles. The visibly turbid aspect and the increase in the polydispersity index for the $\mathrm{NC}$ formulation of $5.0 \mathrm{mg} / \mathrm{ml}$ are also factors that confirm the NC aggregation phenomenon. A further increase in Hf concentration to $10.0 \mathrm{mg} / \mathrm{ml}$ increased the absolute value of the $\zeta$ potential responsible for their interfacial colloidal stability against aggregation, also resulting in a slightly smaller size and polydispersity as compared to that of $5.0 \mathrm{mg} / \mathrm{ml} \mathrm{NC}$. This suggests that $\mathrm{Hf}$ plays a role in the surface charge of $\mathrm{NC}$ formulation above $1 \mathrm{mg} / \mathrm{ml}$ indicating that a part of the drug loaded seems to be associated with the surface of the systems, thus increasing the number of positive charges.

\section{Determination of acute lethal dose $\left(L D_{50}\right)$}

To determine the acute lethal dose for rats, different doses of Hf formulations were IV administered. It was clearly observed that $\mathrm{Hf} . \mathrm{HCl}$ solution induced ataxia, breathing rate alterations, convulsion and death. The percentage of deaths was dosedependent for both $\mathrm{Hf}$ formulations. The observed $\mathrm{LD}_{100}$ for $\mathrm{Hf}$. $\mathrm{HCl}$ was $200 \mathrm{mg} / \mathrm{kg}$ (Fig. 1) and the mean time to death was $30 \mathrm{~min}$. The calculated $\mathrm{LD}_{50}$ was $154 \mathrm{mg} / \mathrm{kg}$ for $\mathrm{Hf} . \mathrm{HCl}$

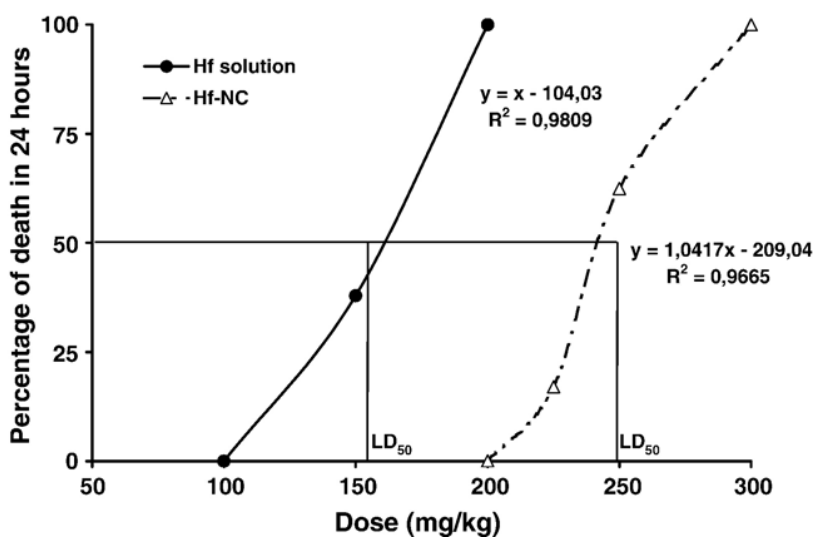

Fig. 1. Lethal dose $\left(\mathrm{LD}_{50}\right)$ of different formulations of halofantrine after IV administration in adults male Wistar rats $(n=8$ for each dose). solution. The $\mathrm{LD}_{100}$ for Hf-NC was $300 \mathrm{mg} / \mathrm{kg}$ (Fig. 1) and the mean time to death was $1 \mathrm{~h} 30 \mathrm{~min}$. Hf-NC induced death only at doses higher than $200 \mathrm{mg} / \mathrm{kg}$ in a dose-dependent manner. The $\mathrm{LD}_{50}$ calculated for Hf-NC was $249 \mathrm{mg} / \mathrm{kg}$. These results indicate that the association of Hf within nanocapsules was able to increase $\mathrm{LD}_{50}$ and thus reduce general in vivo toxicity.

\section{Antimalarial efficacy of NC formulations}

All halofantrine formulations showed efficacy as compared to controls at the dose of $1 \mathrm{mg} / \mathrm{kg}$ (Fig. 2). Moreover, Hf loaded PCL NC reduced significantly $(P<0.05)$ parasitemia over the experimental period compared to Hf loaded PLA-PEG $\mathrm{NC}$ and Hf solution (Table 2). All animals treated with Hf loaded PCL NC survived up to 25 days post-infection. The Hf loaded PLA-PEG NC and Hf solution failed to cure the animals; parasitemia once again began to increase 2 days after treatment. Survival rate was also observed to be lower when compared to the group treated with Hf loaded in PCL NC (Table 2).

\section{Determination of cardiovascular parameters}

Halofantrine in solution caused a significant dose-dependent prolongation of QT and PR intervals of the ECG, which took effect soon after the injection and accumulated over time during the evaluation period $(30 \mathrm{~min})$. The profile of QT and PR alterations induced by $\mathrm{Hf}$ was very similar. This prolongation was significantly $(P<0.002)$ reduced when Hf was administered entrapped in $\mathrm{NC}$ formulations (Fig. 3A and $\mathrm{C}$ ). $\mathrm{Hf}$ associated with $\mathrm{NC}$ reduced the QT prolongation by $77 \%$ and $85 \%$ at $5 \mathrm{~min}$ after the injection of 100 and $150 \mathrm{mg} / \mathrm{kg}$, respectively. For the PR interval, the reduction was $67 \%$ and $71 \%$ for the same doses. The alteration of these parameters observed after Hf-NC administration did not occur in a dosedependent manner. Likewise, doses used were not significantly different from the control groups (Fig. 3A and C). Moreover, there was no significant alteration of ECG parameters in control groups which received vehicles of unloaded nanocapsules or solvents of $\mathrm{Hf} . \mathrm{HCl}$ (Fig. 3). The QRS interval was also

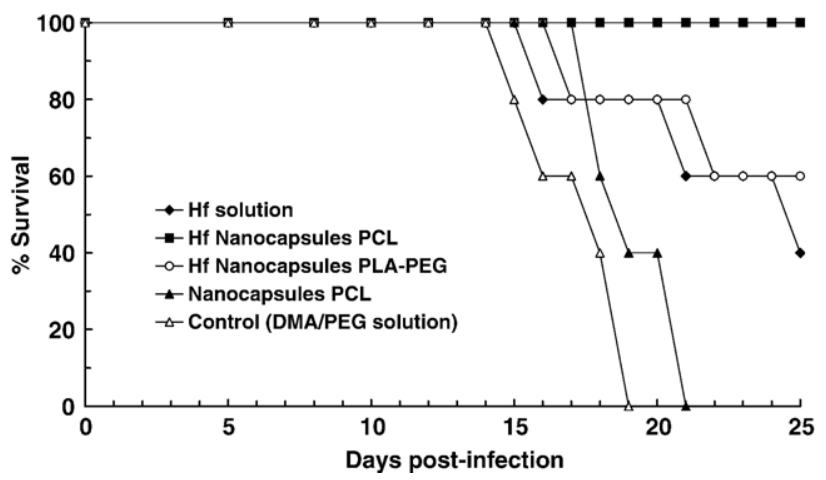

Fig. 2. Survival of $P$. berghei-infected Swiss mice after treatment with halofantrine IV (single dose of $1 \mathrm{mg} / \mathrm{ml}$ ) as compared to control groups. Mice were treated in day three post-infection with 1 million parasitized red blood cells. Each group consisted of 5 mice. Controls with unloaded NC received $0.6 \mathrm{mg}$ of polymer per mouse. 
Table 2

Antimalarial activities of different formulations in $P$. berghei-infected mice after a single IV $1 \mathrm{mg} / \mathrm{kg}$ dose of halofantrine

\begin{tabular}{|c|c|c|c|c|c|c|c|}
\hline \multirow[t]{2}{*}{ Formulations } & \multirow{2}{*}{$\begin{array}{l}\text { MST } \\
\text { (days) }^{\#}\end{array}$} & \multirow{2}{*}{$\begin{array}{l}N^{\circ} \\
\text { survivors }\end{array}$} & \multicolumn{5}{|c|}{ Mean parasitemia $(\%) \pm \mathrm{SD}$ on day } \\
\hline & & & 3 & 5 & 10 & 14 & 25 \\
\hline Hf solution ( $\mathrm{Hf} . \mathrm{HCl})$ & $\mathrm{Nd}$ & $2 / 5$ & $8.9 \pm 3.7^{a}$ & $1.3 \pm 0.1^{b}$ & $4.3 \pm 1.2^{b}$ & $16.5 \pm 7.1^{a}$ & $36.0 \pm 4.0$ \\
\hline Hf PCL NC & $>25$ & $5 / 5$ & $9.0 \pm 2.4^{a}$ & $0.6 \pm 0.3^{b}$ & $0.3 \pm 0.5^{b, c}$ & $0.8 \pm 1.2^{b, c}$ & $6.4 \pm 9.0^{c}$ \\
\hline Hf PLA-PEG NC & $\mathrm{Nd}$ & $3 / 5$ & $10.1 \pm 2.6^{a}$ & $1.6 \pm 0.5^{b}$ & $5.4 \pm 6.8^{b}$ & $11.3 \pm 7.4^{a}$ & $23.0 \pm 3.2$ \\
\hline Unloaded PCL NC & $19(18-21)$ & $0 / 5$ & $9.2 \pm 3.8$ & $9.5 \pm 3.7$ & $13.8 \pm 4.8$ & $19.6 \pm 4.3$ & - \\
\hline Untreated control & $17(15-19)$ & $0 / 5$ & $7.4 \pm 2.6$ & $11.5 \pm 3.1$ & $14.5 \pm 6.1$ & $22.6 \pm 7.9$ & - \\
\hline
\end{tabular}

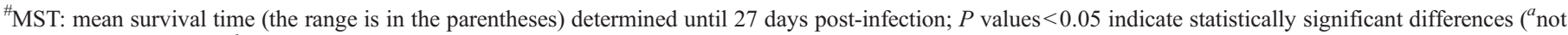
different from controls; ${ }^{b}$ different from controls; ${ }^{c}$ different from Hf PLA-PEG NC and Hf solution). Nd: not determined.

significantly different between $\mathrm{Hf} . \mathrm{HCl}$ solution and $\mathrm{Hf}-\mathrm{NC}$ for the two doses administered (Table 3). According to Abernethy et al. (2001), the $\mathrm{QT}_{\mathrm{c}}$ can be calculated either by the Fridericia correction, for $\mathrm{RR}<500 \mathrm{~ms}$, or by the Bazzett formula, for $\mathrm{RR}>500 \mathrm{~ms}$. The values for the RR parameter of the ECG found in our experiments were consistently lower than $500 \mathrm{~ms}$, thus confirming the Fridericia formula as the most appropriate method of data correction in our model. Analyses of the data using Fridericia correction formula showed that $100 \mathrm{mg} / \mathrm{kg}$ of Hf. $\mathrm{HCl}$ lead to a significant $(P<0.05)$ alteration of $\mathrm{QT}_{\mathrm{c}}$ observed constantly from $0.5 \mathrm{~min}$ to $2 \mathrm{~min}$ and from $4 \mathrm{~min}$ to $15 \mathrm{~min}$ (Fig. 3B). In contrast, Hf-NC did not induce a significant alteration of $\mathrm{QT}_{\mathrm{c}}$ at any time during the $30 \mathrm{~min}$ of observation after IV administration. In fact, the marked and progressive increase in bradycardia observed after Hf injection masked the real variation that demonstrated the reduction of cardiotoxicity in rats receiving $\mathrm{Hf}$ in $\mathrm{NC}$ formulation. Bradycardia has also been observed in malaria patients receiving parenteral halofantrine (Krishna et al., 1993).

Table 3 details the absolute values of cardiovascular parameters measured before and after the administration of each dose and formulation of Hf. Significant and pronounced variation in arterial BP and heart rate was observed after IV administration of $\mathrm{Hf}$ solution. The changes from baseline of arterial BP 7 min after the IV injections are illustrated in Fig. 4. All Hf formulations and doses used in this study induced a significant reduction of diastolic and systolic BP. At $5 \mathrm{~min}$ after drug injection, Hf-NC reduced the diastolic BP by around $41 \%$ and $68 \%$ and systolic BP by around $40 \%$ and $71 \%$ for 100 and $150 \mathrm{mg} / \mathrm{kg}$, respectively. The absolute values of BP presented in Table 3 show that the reduction was maintained. The same profile was observed for heart rate and all the $\mathrm{Hf}$ formulations induced bradycardia. This effect on heart rate was reduced $58 \%$ and $75 \%$ when the drug was injected in $\mathrm{NC}$ formulation at doses of 100 and $150 \mathrm{mg} / \mathrm{kg}$, respectively.

Fig. 5 shows sample traces of ECG from representative rats from the different experimental groups that received $150 \mathrm{mg} / \mathrm{kg}$ of Hf.HCl or Hf-NC.

\section{Discussion}

Halofantrine is the most cardiotoxic drug among those frequently used to treat malaria (Touze et al., 2002). Its ability to induce a QT interval prolongation has already been reported in anaesthetized guinea-pigs and rabbits (Batey et al., 1997; Lightbown et al., 2001). The mechanism of cardiotoxicity of the $\mathrm{Hf}$ is particularly based on the potassium channel inhibition (Wesche et al., 2000), responsible for potential action repolarization onset which determines the QT interval (Crumb and Cavero, 1999). In fact, in our work, the main objective was to study the modification of the $\mathrm{Hf}$ effect on the cardiovascular system, caused by its entrapment in $\mathrm{NC}$, presuming that the $\mathrm{Hf}$ mechanism of action has not been altered. Studies concerning general toxicity and Hf pharmacokinetics parameters have already been performed in a rat model (Karbwang and Bangchang, 1994; Brocks and Toni, 1999); however, the specific investigation of QT interval prolongation provoked by $\mathrm{Hf}$ in this species is first reported here.

One of the main problems associated with Hf is its low solubility in water. It is extremely lipophilic and, although it can be dissolved in the solvent system used to prepare the parenteral formulation (Krishna et al., 1993), it will not remain in solution upon dilution with physiological salt solutions (Batey et al., 1997). Krishna used dimethylacetamide-polyethyleneglycol $(40: 60 \mathrm{v} / \mathrm{v})$ diluted in 5\% $\mathrm{w} / \mathrm{v}$ dextrose; however, local toxicity was a significant problem after IV infusion and this solution had to be prepared extemporaneously due the rapid precipitation of the drug. Mosqueira et al. (2004) showed that the encapsulation of $\mathrm{Hf}$ free base in polymeric nanocapsules resulted in 6-fold increases in the AUC after IV administration in mice despite the PLA or PLA-PEG polymer used. In fact, the nanocapsules of poly- $\varepsilon$-caprolactone (PCL) obtained here were as efficacious as PLA-PEG NC against $P$. berghei in the murine model as shown in Fig. 1 and Table 2. Particularly PCL NC showed a greater efficacy than Hf solution and PLA-PEG NC in prolonging survival and reducing parasitemia. The PCL polymer was also chosen here because it is very hydrophobic, producing $\mathrm{NC}$ that most likely accumulates quickly in mononuclear phagocyte system (MPS). Thus, this property was expected to alter the biodistribution of $\mathrm{Hf}$ when compared to its solution, reducing $\mathrm{Hf}$ interaction with the heart. Furthermore, PCL is affordable and possesses a slow rate of degradation as compared to PLA (Lemoine et al., 1996). The drug load was not significantly different between the NC formulations $(P<0.05)$ (data not shown) and was consistently higher than $98 \%$ in all NC, showing that Hf possesses a high affinity for this type of nanocarrier. The polydispersity index and mean size of $\mathrm{NC}$ were quite similar to previously prepared $\mathrm{Hf}$ loaded poly (D,L-lactic acid) NC (Mosqueira et al., 2006). According to Krishna et al. (1993), the dose used in humans for 


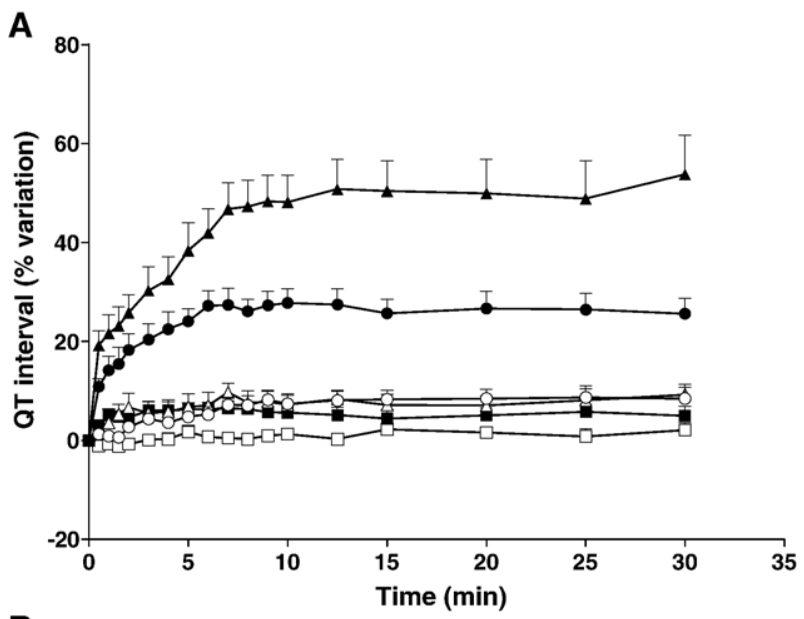

B
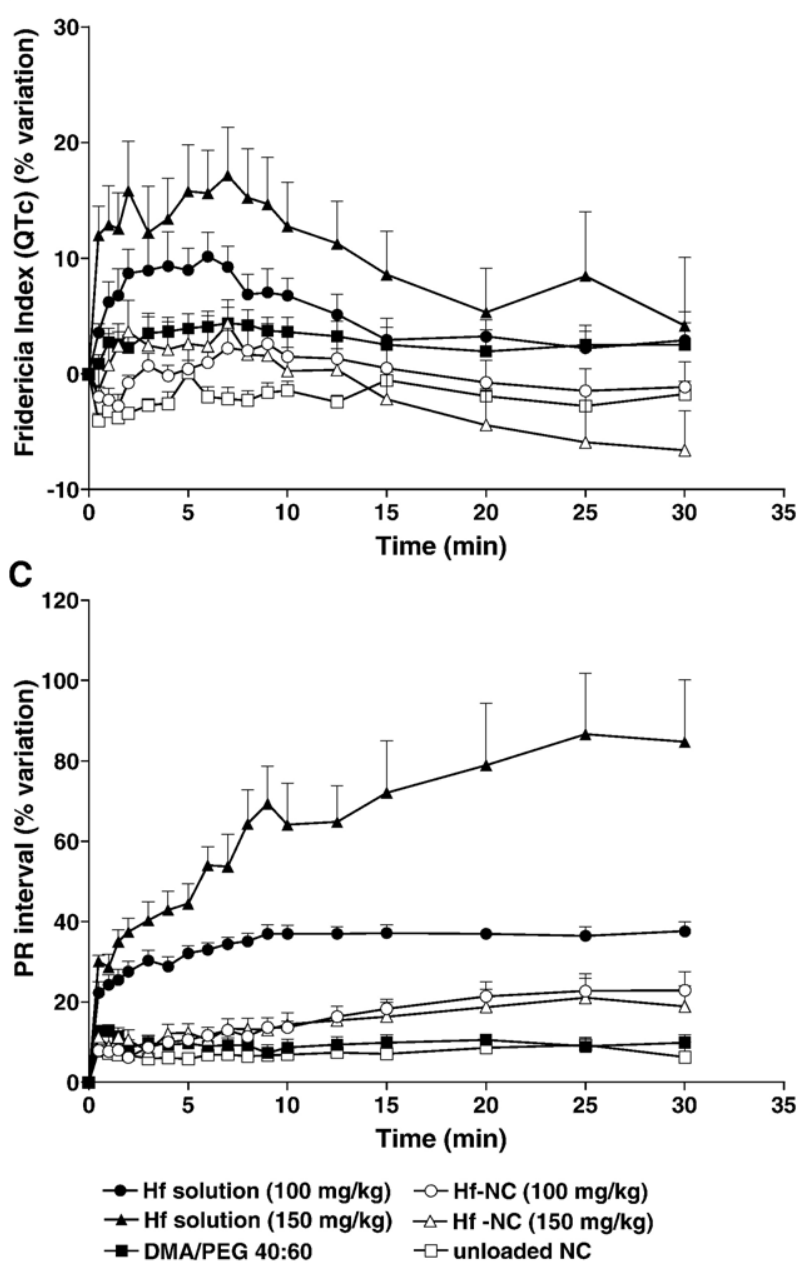

Fig. 3. Percentage variation of QT interval (A), Fridericia index (B) and PR interval (C) of the ECG of anaesthetized male rats. The values represent means \pm S.E.M. (standard error mean) for $30 \mathrm{~min}$ after IV injection of halofantrine solution (Hf. $\mathrm{HCl})$, halofantrine entrapped in nanocapsules (Hf-NC) in doses of $100 \mathrm{mg} / \mathrm{kg}$ $(n=6)$ or $150 \mathrm{mg} / \mathrm{kg}(n=8)$, unloaded NC $(n=8)$ and DMA/PEG solution $(n=8)$.

the treatment of falciparum malaria is $1 \mathrm{mg} / \mathrm{kg}$ infused over $1 \mathrm{~h}$ by IV route. In the NC preparation described here $(10 \mathrm{mg} / \mathrm{ml})$, the volume to be administered in bolus would be around $7 \mathrm{ml}$ for an adult. In all experiments, $10 \mathrm{mg} / \mathrm{ml} \mathrm{NC}$ with the same positive surface charge were used. This could influence their distribution; however, NC generally present a zeta potential closer to zero in physiological pH and ionic strength (Mosqueira et al., 2001). From the physico-chemical characterization (Table 1), the best formulation corresponds to $1 \mathrm{mg} \mathrm{Hf} / \mathrm{ml}$ of colloidal suspension due to the fact that it is monodispersed $(\mathrm{PI}<0.3)$ and zeta potential was not significantly altered, indicating that $\mathrm{Hf}$ was effectively loaded inside NC. As an alternative, a volume of $70 \mathrm{ml}$, also suitable for humans, could be infused.

Adverse effects observed in animal behaviour that receive doses under lethal doses were observed in all animals that received an IV free $\mathrm{Hf}$, with the degree varying in relation to the dose. To the contrary, these effects were not observed in animals that received Hf-NC, except in rats that died after receiving doses higher than $225 \mathrm{mg} / \mathrm{kg}$. The maximum tolerated dose was almost $50 \%$ higher for Hf-NC when compared to free Hf solution. Our results are in agreement with Mosqueira et al. (2004) who showed the reduced general toxicity of Hf-NC in mice.

The present study is the first to demonstrate that a polymeric nanocarrier formulation is able to reduce the cardiac toxicity of a drug evaluated through the analysis of the QT interval prolongation in the ECG. It clearly demonstrates that $\mathrm{Hf} . \mathrm{HCl}$

Table 3

Means of absolute values of blood pressure, heart rate and electrocardiographic parameters measured before and after IV injection of $\mathrm{Hf}$ solution or $\mathrm{Hf}$ nanocapsules at different times

\begin{tabular}{|c|c|c|c|c|c|}
\hline \multirow[t]{2}{*}{ Parameters } & \multirow{2}{*}{$\begin{array}{l}\text { Time } \\
(\mathrm{min})\end{array}$} & \multicolumn{2}{|l|}{$100 \mathrm{mg} / \mathrm{kg}^{a}$} & \multicolumn{2}{|l|}{$150 \mathrm{mg} / \mathrm{kg}^{b}$} \\
\hline & & $\mathrm{Hf}-\mathrm{HCl}$ & Hf-NC & $\mathrm{Hf}-\mathrm{HCl}$ & $\mathrm{Hf}-\mathrm{NC}$ \\
\hline \multirow{4}{*}{$\begin{array}{l}\text { Heart rate } \\
\qquad\left(\text { beats } \min ^{-1}\right)\end{array}$} & 0 & $376 \pm 14.7$ & $359 \pm 21.2$ & $289 \pm 21.3$ & $247 \pm 17.0$ \\
\hline & 5 & $258 \pm 18.3$ & $312 \pm 19.1^{* *}$ & $168 \pm 8.9$ & $221 \pm 19.5$ \\
\hline & 15 & $210 \pm 21.1$ & $280 \pm 17.3^{* *}$ & $107 \pm 8.7$ & $194 \pm 24.7^{*}$ \\
\hline & 25 & $204 \pm 17.7$ & $261 \pm 16.2^{* *}$ & $91 \pm 5.3$ & $174 \pm 29.1^{* *}$ \\
\hline \multirow{4}{*}{$\begin{array}{r}\text { Systolic BP } \\
(\mathrm{mm} \mathrm{Hg})\end{array}$} & 0 & $116 \pm 4.8$ & $122 \pm 7.5$ & $124 \pm 8.8$ & $130 \pm 11.9$ \\
\hline & 5 & $85 \pm 2.5$ & $94 \pm 5.8^{*}$ & $69 \pm 5.5$ & $113 \pm 15.0^{*}$ \\
\hline & 15 & $81 \pm 3.2$ & $94 \pm 3.8^{*}$ & $68 \pm 6.2$ & $99 \pm 16.0^{*}$ \\
\hline & 25 & $72 \pm 3.4$ & $95 \pm 4.0$ & $73 \pm 6.1$ & $98 \pm 17.7$ \\
\hline \multirow{4}{*}{$\begin{array}{l}\text { Diastolic BP } \\
\quad(\mathrm{mm} \mathrm{Hg})\end{array}$} & 0 & $82 \pm 3.5$ & $83 \pm 4.8$ & $89 \pm 8.2$ & $91 \pm 7.9$ \\
\hline & 5 & $27 \pm 2.4$ & $50 \pm 4.0 * *$ & $18 \pm 2.0$ & $68 \pm 14.2 * *$ \\
\hline & 15 & $38 \pm 3.3$ & $51 \pm 2.8^{*}$ & $17 \pm 3.1$ & $61 \pm 13.8^{* *}$ \\
\hline & 25 & $43 \pm 1.9$ & $53 \pm 3.4^{*}$ & $18 \pm 1.3$ & $57 \pm 13.8^{*}$ \\
\hline \multirow{4}{*}{ QT (ms) } & 0 & $72 \pm 1.7$ & $73 \pm 0.9$ & $82 \pm 4.4$ & $70 \pm 2.7$ \\
\hline & 5 & $89 \pm 2.8$ & $77 \pm 1.1^{* *}$ & $114 \pm 7.8$ & $74 \pm 3.6^{* *}$ \\
\hline & 15 & $90 \pm 3.1$ & $79 \pm 1.0 * *$ & $122 \pm 8.7$ & $75 \pm 3.6^{* *}$ \\
\hline & 25 & $91 \pm 3.1$ & $80 \pm 0.9^{* *}$ & $122 \pm 14.2$ & $75 \pm 3.9^{* *}$ \\
\hline \multirow[t]{4}{*}{$\mathrm{QT}_{\mathrm{c}}(\mathrm{ms})$} & 0 & $132 \pm 2.7$ & $133 \pm 2.3$ & $148 \pm 6.6$ & $127 \pm 3.7$ \\
\hline & 5 & $144 \pm 3.4$ & $134 \pm 2.8^{* *}$ & $171 \pm 9.3$ & $130 \pm 5.2$ \\
\hline & 15 & $136 \pm 3.4$ & $134 \pm 3.5$ & $158 \pm 9.0$ & $124 \pm 4.8$ \\
\hline & 25 & $135 \pm 2.6$ & $131 \pm 3.0$ & $159 \pm 10.4$ & $119 \pm 5.3$ \\
\hline \multirow[t]{4}{*}{ PR (ms) } & 0 & $63 \pm 1.8$ & $66 \pm 2.4$ & $66 \pm 3.5$ & $61 \pm 2.8$ \\
\hline & 5 & $83 \pm 3.5$ & $73 \pm 2.5^{* *}$ & $96 \pm 6.9$ & $69 \pm 4.3^{* *}$ \\
\hline & 5 & $86 \pm 3.7$ & $78 \pm 3.8^{* *}$ & $115 \pm 15.6$ & $72 \pm 4.9^{* *}$ \\
\hline & 25 & $86 \pm 3.5$ & $81 \pm 5.2^{* *}$ & $129 \pm 15.7$ & $75 \pm 5.9 * *$ \\
\hline \multirow[t]{4}{*}{ QRS (ms) } & 0 & $30 \pm 1.1$ & $28 \pm 1.8$ & $27 \pm 1.2$ & $23 \pm 1.1$ \\
\hline & 5 & $38 \pm 1.8$ & $28 \pm 1.1^{* *}$ & $37 \pm 1.6$ & $25 \pm 1.1^{* *}$ \\
\hline & 15 & $36 \pm 1.2$ & $30 \pm 1.3^{* *}$ & $35 \pm 2.1$ & $25 \pm 1.1^{*}$ \\
\hline & 25 & $34 \pm 1.1$ & $30 \pm 1.2 * *$ & $33 \pm 13.0$ & $25 \pm 1.0 * *$ \\
\hline
\end{tabular}

The values represent the mean \pm S.E.M.; $a(n=6)$ and $b(n=8)$ indicate the number of viable animals in different groups. ${ }^{*} P$ value $\leq 0.05$, and $* * P$ value $\leq 0.01$ indicate statistically significant differences. 
provokes a prolongation of the QT interval in rats and that by associating the drug within the $\mathrm{NC}$, the cardiovascular effect is diminished, consequently reducing the general toxicity. The results showed that a dose-dependent prolongation of the QT interval, at the high dosage level used in this study, was in fact induced, confirming previous observations (Batey et al., 1997; Lightbown et al., 2001), whereas a significantly reduced QT prolongation was observed for both doses of Hf-NC tested (Table 3). Our results demonstrate that the larger the dose administered, the larger the protection afforded by nanoencapsulation. The Hf solvent did not induce significant alterations in the electrophysiological cardiac function, nor did unloaded NC.

Furthermore, the highest dose of $\mathrm{Hf} . \mathrm{HCl}$ used in this study increased the PR interval, as was also observed in guinea-pigs (Batey et al., 1997) and rabbits (Lightbown et al., 2001). No significant variation of QRS was observed after administration of $150 \mathrm{mg} / \mathrm{kg}$ of free $\mathrm{Hf}$ to rats. Additionally, $\mathrm{Hf} . \mathrm{HCl}$ induced important variations of blood pressure and heart rate in rats in vivo, which had not been observed previously in guinea-pigs nor reported in humans (Batey et al., 1997; Krishna et al., 1993). The high doses of Hf used are most likely the cause of the severe hypotension and bradycardia observed. Even when Hf-NC was injected, a reduction of blood pressure and heart rate was observed, but this was not life-threatening, in contrast to the situation where a free Hf solution was injected. Batey et al. (1997) argued that the QT interval was more sensitive to the effects of $\mathrm{Hf}$ than was the heart rate at lower doses. In our experiments, the much higher doses used (100 and $150 \mathrm{mg} / \mathrm{kg})$ induced significant variation in heart rate and QT interval. In fact, bradycardia progressively increased, as also observed by Batey et al. (1997), while the peak effect on QT variation was observed within 5 to $7 \mathrm{~min}$ after administration.

The reduction of the cardiovascular alterations observed after injection of Hf-NC is probably due to the ability of nanocarriers to modify the distribution of the entrapped drug in the body (Mosqueira et al., 2004). The reduction of toxic effects resulting

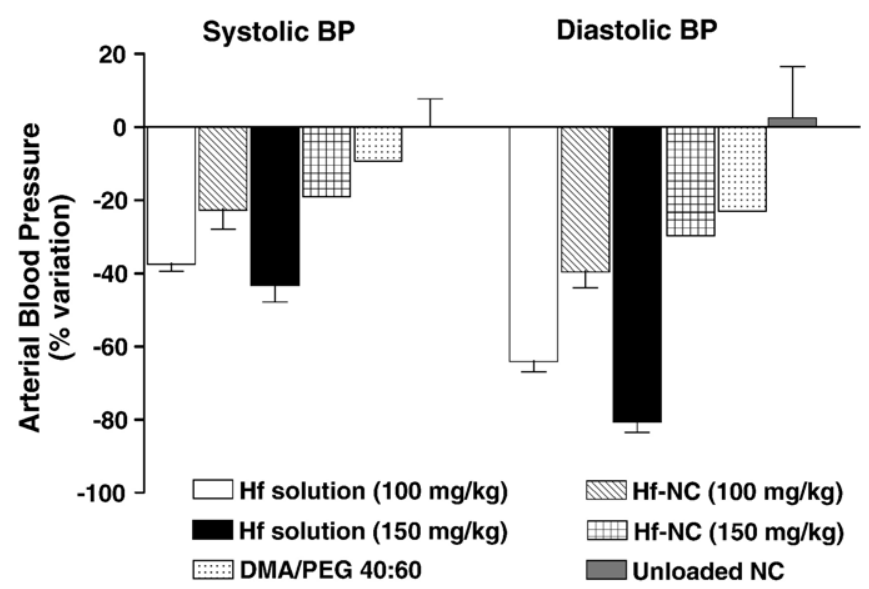

Fig. 4. Percentage variation of the arterial blood pressure observed 7 min after IV administration of halofantrine solution ( $\mathrm{Hf} . \mathrm{HCl}$ ), halofantrine entrapped in nanocapsules (Hf-NC) in doses of $100 \mathrm{mg} / \mathrm{kg}(n=6)$ or $150 \mathrm{mg} / \mathrm{kg}(n=8)$, unloaded $\mathrm{NC}(n=8)$ and DMA/PEG solution $(n=8) .{ }^{*} P<0.05$ compared to the Hf-NC group.
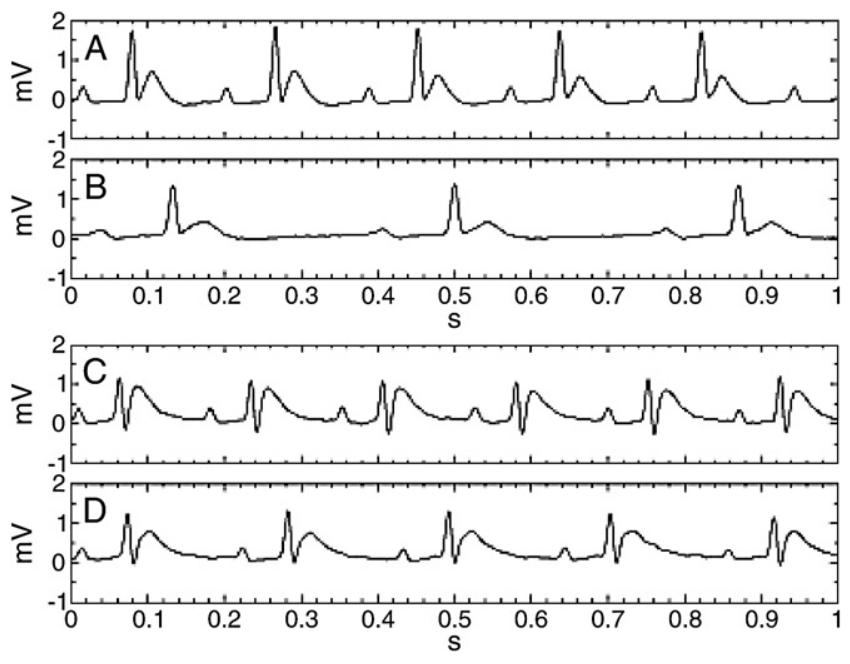

Fig. 5. Representative traces of ECG showing the effects of halofantrine on the cardiovascular parameters during the control period (A and C) (before administering the drug) and $7 \mathrm{~min}$ after IV injection of $150 \mathrm{mg} / \mathrm{kg}$ of $\mathrm{Hf} . \mathrm{HCl}$ (B) and Hf-NC (D).

from Hf-NC treatment could be attributed to a lower free fraction of the drug available for association with the cardiac tissue as compared with the administration of the drug as a solution. From its physico-chemical properties, PCL NC was most likely cleared from blood circulation by MPS, thus reducing the availability of free $\mathrm{Hf}$ to interact with heart tissue. There is also some evidence that the free Hf binds extensively to lipoproteins, mainly low- and high-density lipoproteins, according to the studies performed by Brocks and Wasan (2002). It is probable that the association of the $\mathrm{Hf}$ with the oily core of nanocapsules reduces the amount of drug bound to lipoproteins in the blood and consequently reduces the fraction that would be transported to the heart tissue through LDL receptors. This hypothesis is supported by the studies concerning the disposition of $\mathrm{Hf}$ in hyperlipidemic rats (Porter and Charman, 1997).

\section{Conclusion}

The most important result emerging from this work is the ability of a polymeric colloidal system, nanocapsules, to ensure a reduced cardiotoxic profile for $\mathrm{Hf}$ when compared to the free drug at the same high doses, showing that drug distribution seems to be modified by these nanocarriers. Therefore, the results clearly demonstrate the effects of free $\mathrm{Hf}$ as compared to those of Hf-NC. It can be speculated that lower doses of Hf entrapped in $\mathrm{NC}$ could be used by IV route, to obtain the same effect of Hf solution in humans. Therefore, the development of nanocarriers which are able to reduce cardiac side effects represents a potential interest in the future production of safer IV malaria treatments.

\section{Acknowledgements}

The first author is the recipient of a CAPES scholarship. We wish to thank FAPEMIG-MG for its grant (CDS-217/02). This work has also received financial support from the UNDP/World 
Bank/WHO Special Program for Research and Training in Tropical Diseases (TDR) (ID A00790).

\section{References}

Abernethy, D.R., Wesche, D.L., Barbey, J.T., Ohrt, C., Mohanty, S., Pezzullo, J.C., Schuster, B.G., 2001. Stereoselective halofantrine disposition an effect: concentration-related QTc prolongation. British Journal of Pharmacology 51 (3), 231-237.

Barratt, G.M., 2003. Colloidal drug carriers: achievements and perspectives. Cellular and Molecular Life Sciences 60, 21-37.

Batey, A.J., Lightbown, I.D., Lambert, J.P., Edwards, G., Coker, S.J, 1997. Comparison of the acute cardiotoxicity of the antimalarial drug halofantrine in vitro and in vivo in anaesthetized guinea-pigs. British Journal of Pharmacology 122 (3), 563-569.

Brocks, D.R., Toni, J.W., 1999. Pharmacokinetics of halofantrine in the rats: stereoselectivity and interspecies comparisons. Biopharmaceutics and Drug Disposition 20 (3), 165-169.

Brocks, D.R., Wasan, K.M., 2002. The influence of lipids on stereoselective pharmacokinetics of halofantrine: important implications in food-effect studies involving drugs that bind to lipoproteins. Journal of Pharmaceutical Sciences 91 (8), 1817-1826.

Bryson, H.M., Goa, K.L., 1992. Halofantrine: a review of its antimalarial activity, pharmacokinetic properties and therapeutic potential. Drugs 43 (20), 236-258.

Crumb, W., Cavero, I., 1999. QT interval prolongation by non-cardiovascular drugs: issues and solutions for novel drug development. Pharmaceutical Science and Technology Today 2 (7), 270-280.

Fessi, H., Puisieux, F., Devissaguet, J.P., Ammoury, N., Benita, S., 1989. Nanocapsule formation by interfacial polymer deposition following solvent displacement. International Journal of Pharmaceutics 55, R1-R4.

Greenwood, B.M., Bojang, K., Whitty, C.J.M., Targett, G.A.T., 2005. Malaria. Lancet 365 (9469), 1487-1498.

Guerin, P.J., Olliaro, P., Nosten, F., Druilhe, P., Laxminarayan, R., Binka, F., Kilama, W.L., Ford, N., White, N.J., 2002. Malaria: current status of control, diagnosis, treatment, and a proposed agenda for research and development. Lancet Infectious Diseases 2 (9), 564-573.

Humberstone, A.J., Porter, C.J.H., Charman, W.N., 1996. A physicochemical basis for the effect of food on the absolute oral bioavailability of halofantrine. Journal of Pharmaceutical Sciences 85 (5), 525-529.

Karbwang, J., Bangchang, K.N., 1994. Clinical pharmacokinetics of halofantrine. Drug Disposition 27 (2), 104-119.

Krishna, S., Ter Kuile, F., Supanaranond, W., Pukrittayakamee, S., TejaIsavadharm, P., Kyle, D., White, N.J., 1993. Pharmacokinetics, efficacy and toxicity of parenteral halofantrine in uncomplicated malaria. British Journal of Clinical Pharmacology 36 (6), 585-591.

Lasic, D.D., 1998. Novel applications of liposomes. Trends in Biotechnology 16 (7), 307-321.

Lemoine, D., François, C., Kedzierewicz, F., Preat, V., Hoffman, M., Maincent, P., 1996. Stability study of nanoparticles of poly( $\varepsilon$-caprolactone), poly(D,Llactide) and poly(D,L-lactide-co-glycolide). Biomaterials 17, 2191-2197.

Lightbown, I.D., Lambert, J.P., Edwards, G., Coker, S.J., 2001. Potentiation of halofantrine-induced QTc prolongation by mefloquine: correlation with blood concentrations of halofantrine. British Journal of Pharmacology 132 (1), 197-204.

Matson, P.A., Luby, S.P., Redd, S.C., Rolka, H.R., Meriwether, R.A., 1996. Cardiac effects of standard-dose halofantrine therapy. American Journal of Tropical Medicine and Hygiene 54 (3), 229-231.

Mberu, E.K., Muhia, D.K., 1992. Measurement of halofantrine and its major metabolite desbutylhalofantrine in plasma and blood by high-performance liquid chromatography: a new methodology. Journal of Chromatography 581 (1), 156-160.

Mosqueira, V.C.F., Legrand, P., Gulik, A., Bourdon, O., Gref, R., Labarre, D., Barratt, G., 2001. Relationship between complement activation, cellular uptake and surface physicochemical aspects of novel PEG-modified nanocapsules. Biomaterials 22, 2967-2979.

Mosqueira, V.C.F., Loiseau, P.M., Bories, C., Legrand, P., Devissaguet, J.P., Barratt, G., 2004. Efficacy and pharmacokinetics of intravenous nanocapsule formulations of halofantrine in Plasmodium berghei-infected mice. Antimicrobial Agents and Chemotherapy 48 (4), 1222-1228.

Mosqueira, V.C.F., Legrand, P., Barratt, G., 2006. Surface-modified and conventional nanocapsules as novel formulations for parenteral delivery of halofantrine. Journal of Nanoscience and Nanotechnology 6 (9-10), 3193-3202.

Nosten, F., ter Kuile, F.O., Luxemburger, C., Woodrow, C., Kyle, D.E., Chongsuphajaisiddhi, T., White, N.J., 1993. Cardiac effects of antimalarial treatment with halofantrine. Lancet 341 (8852), 1054-1056.

Olivier, C., Rizk, C., Zhang, D., Jacqz-Aigrain, E., 1999. Long QTc interval complicating halofantrine therapy in 2 children with Plasmodium falciparum malaria. Archives de Pediatrie 6 (9), 966-970.

Porter, C.J.H., Charman, W.N., 1997. Uptake of drugs into the intestinal lymphatics after oral administration. Advanced Drug Delivery Reviews 25 (1), 71-89.

Porter, C.J.H., Charman, S.A., Charman, W.N., 1996. Lymphatic transport of halofantrine in the triple-cannulated anaesthetized rat model: effect of lipid vehicle dispersion. Journal of Pharmaceutical Sciences 85 (4), 351-356.

ter Kuile, F.O., Dolan, G., Nosten, F., Edstein, M.D., Luxemburger, C., Phaipun, L., Chongsuphajaisiddhi, T., Webster, H.K., White, N.J., 1993. Halofantrine versus mefloquine in the treatment of multi drug-resistant falciparum malaria. Lancet 341 (8852), 1044-1049.

Touze, J.-E., Heno, P., Fourcade, L., Deharo, J.-C., Thomas, G., Bohan, S., Paule, P., Riviere, P., Kouassi, E., Buguet, A., 2002. The effects of antimalarial drugs on ventricular repolarization. American Journal of Tropical Medicine and Hygiene 67 (1), 54-60.

Warrell, D.A., Molyneux, M., Beales, P.F., 1990. Severe and complicated malaria. Transactions of the Royal Society of Tropical Medicine and Hygiene 84 (2), 1-65.

Wesche, D.L., Schuster, B.G., Wang, W.X., Woosley, R.L., 2000. Mechanism of cardiotoxicity of halofantrine. Clinical Pharmacology and Therapeutics 67 (5), 521-529.

Wongsrichanalai, C., Pickard, A.L., Wernsdorfer, W.H., Meshnick, S.R., 2002. Epidemiology of drug-resistant Malaria. Lancet Infectious Disease 2 (4), 209-218. 